\title{
Perceptions of Traumatic Brain Injury among Preventive Medicine Program Residents in Aseer Region, Kingdom of Saudi Arabia
}

\author{
Syed Esam Mahmood ${ }^{1}$, Shehata F. Shehata ${ }^{2}$, Ausaf Ahmad ${ }^{3}$, Mohammed Algethami', \\ Abdullah A. Alsabaani ${ }^{5}$, Hassan M. Al Shaiban ${ }^{6}$, Najim Z. Alshahrani ${ }^{7}$, Rishi Kumar Bharti ${ }^{8}$ \\ Irfan Ahmad', Razia Aftab ${ }^{10}$
}

1,5,8,10 Department of Family \& Community Medicine, College of Medicine, King Khalid University, Abha, Saudi Arabia. ${ }^{2}$ Department of Family \& Community Medicine, College of Medicine, King Khalid University, Abha, Saudi Arabia and Biostatistics Department, High Institute of Public Health, Alexandria University. ${ }^{3}$ Department of Community Medicine, Integral Institute of Medical Sciences and Research, Integral University,Lucknow, Uttar Pradesh, India. ${ }^{4}$ Department of Medicine, Joint Program, Aseer Region, Abha, Saudi Arabia. ${ }^{6}$ Joint Program of Preventive Medicine of postgraduates, Aseer Program, Abha 61421, Saudi Arabia. ${ }^{7}$ Department of Family and Community Medicine, University of Jeddah, Jeddah, Saudi Arabia \& Joint Program of Preventive Medicine, Saudi Commission for Health Specialties, Jeddah, Saudi Arabia. ${ }^{9}$ Department of Clinical Laboratory Sciences, College of Applied Medical Sciences, King Khalid University, Abha, KSA.

\section{ABSTRACT}

\section{BACKGROUND}

Traumatic Brain Injury (TBI) is a recognized public health problem with the increasing burden of disability and death occurring globally. We wanted to assess the perceptions about traumatic brain injury and also find its overall awareness among preventive medicine residents.

\section{METHODS}

This cross-sectional study involved preventive medicine program residents of Aseer region. Participants were recruited from Oct 1 2019, to Sept 30 2019. After giving a brief explanation and taking voluntary consent, a 40 item self-reported questionnaire was administered to the participants. Data entry and statistical analysis were performed using Microsoft Excel and SPSS windows version 16.0 software. Descriptive statistics (means, standard deviations) were performed for the patient's age and overall awareness level. Three points Likert scale was used to assess the effects of brain injury, causes and preventive measures as reported by program residents.

\section{RESULTS}

The majority of respondents were less than thirty years of age $(64.7 \%)$ and residing in the R1 level (67.6\%). The number of male respondents was more than three times compared to female respondents. The majority of respondents had good awareness about preventive measures of brain injury (97.1\%) and causes of brain injury (67.6 $\%)$. A higher proportion of respondents were having poor awareness about the effect of brain injury (79.4\%). Overall awareness level regarding brain injury was observed to be $58.8 \%$ among the residents.

\section{CONCLUSIONS}

This study projects the need to strengthen the awareness about TBIs in the preventive program residents. This will provide valuable feedback to the policymakers and the national prevention program managers.

\section{KEY WORDS}

Traumatic Brain Injury, Residents, Preventive Medicine Program
Corresponding Author:

Dr. Ausaf Ahmad,

Department of Community Medicine, Integral Institute of Medical Sciences and Research, Lucknow, UP, India,

E-mail: ausafahmad86@gmail.com

DOI: $10.14260 /$ jemds/2021/612

How to Cite This Article:

Mahmood SE, Shehata SF, Ahmad A, et al. Perceptions of traumatic brain injury among preventive medicine program residents in Aseer region, Kingdom of Saudi Arabia. J Evolution Med Dent Sci 2021;10(35):2994-2998, 10.14260/jemds/2021/612

Submission 05-04-2021, Peer Review 20-07-2021, Acceptance 27-07-2021, Published 30-08-2021.

Copyright (C) 2021 Syed Esam Mahmood et al. This is an open access article distributed under Creative Commons Attribution License [Attribution 4.0 International (CC $B Y 4.0)]$ 


\section{BACKGROUND}

Traumatic Brain Injury (TBI) is a recognized public health problem with the increasing burden of disability and death occurring globally. ${ }^{1}$ Sixty-nine million (95 \% CI 64 - 74 million) individuals suffer from TBI from all causes annually, with the greatest overall disease burden in Southeast Asian and Western Pacific regions. Head injury following road traffic collision is more common and the proportion of TBIs secondary to road traffic collision is likewise greatest in Low Middle-income countries. ${ }^{2}$ In high-income countries, the incidence of TBI due to road traffic incidents has decreased following the successful implementation of preventive measures (legislations, safer roadway infrastructure, car safety measures and helmets); nevertheless, the burden of TBI remains high because of increasing number of elderly patients due to a fall in these countries. ${ }^{3}$ The United Nations Decade of Action for Road Safety (2011 - 2020) aims to reduce to half the 1.3 million traffic related deaths by 2020 through preventive and promotive measures including road safety management, safer vehicles, better - informed road users and an improved post - crash response. 4 Increased awareness amongst policymakers and the general public is essential for the implementation of preventive programs and measures to improve the patient care. Accurate national details a prerequisite for the development and successful implementation of measures aimed to reduce the TBI burden.

Children and adolescents are at increased risk of sustaining a TBI, including concussions. ${ }^{5}$ Most of the TBIs are concussions or other forms of mild TBI. Concussions can have a serious effect on young, developing brains, causing problems that affect a child's thinking, language, learning, behaviour, and / or emotions. ${ }^{6}$ Although most children and adolescents with a concussion recover quickly and fully, some will have severe illness lasting for days to weeks or longer. ${ }^{6}$ Surprisingly, misconceptions about TBI have been reported among healthcare providers involved in the care of patients with TBI in different settings. ${ }^{7}$ TBI is a critical public health problem in Saudi Arabia and has a significant social and economic impact. Eighty-one per cent of deaths in the Kingdom's Ministry of Health hospitals are due to road traffic accidents, ${ }^{8}$ with a TBI mortality of $17.4 \%$. Head and facial injury account for $30 \%$ of all injuries and $26 \%$ of recorded deaths. ${ }^{9}$ A major trauma center in Saudi Arabia reported that $32.1 \%$ of 1,219 patients suffered head injuries and Motor Vehicle Accidents were the leading cause of head injuries (34.2 $\%)^{10}$

With this background, this study was undertaken with the following objectives (1) To assess the perceptions about traumatic brain injury among preventive medicine postgraduates (2) To find the overall awareness about TBI among the postgraduates.

\section{METHODS}

This cross-sectional study was conducted in Aseer Central Hospital (ACH), Kingdom of Saudi Arabia and included the preventive medicine program postgraduates of Aseer region. Postgraduate students enrolled in R1, R2 and R4 levels were recruited from Oct 1 2019, to Sept 30 2019. After getting permission from the Director of the Program, written informed consent was obtained from the preventive medicine postgraduates. Participation was voluntary, and no monetary stipend or incentive was offered to any participant.

\section{Sample Size}

The sample size was calculated according to the following formula -

Sample size $(n)=\frac{\left(z_{1-\alpha / 2}\right)^{2 *}(p)(q)}{(d)^{2}}$

$\mathrm{N}=$ Desired sample size

$Z_{1-\alpha / 2}=$ Critical value and a standard value for the corresponding level of confidence.

(At $95 \%$ CI or $5 \%$ level of significance (type - I error) it is 1.96)

$\mathrm{P}=$ Expected prevalence or based on previous research

$\mathrm{Q}=1-\mathrm{p}$

$\mathrm{D}=$ Margin of error or precision

Where margin of error $=17.0 \%$ and prevalence of disease unknown so it is considered to put $50 \%$. Sample size came out to be 34 .

\section{Data Collection}

After giving a brief explanation about the study, the questionnaire was administered to 34 postgraduate students at the end of their regular classes. The concepts and items were developed based on findings from the prior studies on perceptions and awareness related to TBI. Content validity of the questionnaire was assessed by a panel of four experts and the item-level content validity index (I-CVI) was determined. After pretesting the questionnaire was pilot tested to check reliability of the items. Exploratory factor analysis was used to test for dimensionality using a sample of 5 participants. Participants were asked to read and anonymously complete a 40 item self report questionnaire that was designed to assess the knowledge about causes of TBI, methods which can prevent TBI, its effects, recovery, and so forth. Participants were to choose between the answers 'Yes, 'Know, and 'Don't know for each item. The entire process took less than 40 minutes for each participant.

Overall awareness level of traumatic brain injury scores ranged from 0 - 40 with each correct answer scoring 1 point. Any incorrect, unanswered and unsure responses were scored 0 . The cut-off point for the overall awareness level of traumatic brain injury questionnaire score was 26 , which was obtained from the median score of the pilot study; a score below 26 was considered to be poor awareness, while a score equal or above 26 was considered to be good awareness.

\section{Ethical Statement}

All necessary official permission and ethical approval was obtained before data collection. The objectives of the study were explained to all participants and the investigators assured them that their responses would be fully confidential.

\section{Statistical Analysis}

Data entry and statistical analysis were performed using Microsoft Excel and SPSS windows version 16.0 software. Descriptive statistics (means, standard deviations) were 
performed for patient's age and overall awareness level. Three points Likert scale was used to assess the effects of brain injury, causes and preventive measures as reported by program residents in the Aseer region, Saudi Arabia. Kuder Richardson Formula 20, or KR - 20, was used to measure the reliability of the overall awareness level (Causes of brain injury, preventive measures of brain injury and effect of brain injury).

\section{RESULTS}

\begin{tabular}{|c|ccc|}
\hline Variable & Personal Data & No & \% \\
Age in years & $<30$ years & 22 & $64.7 \%$ \\
& $>30$ years & 12 & $35.3 \%$ \\
& Mean \pm SD & 23 & $67.9 \pm 2.8$ \\
Residency level & R1 & 6 & $17.6 \%$ \\
& R2 & 5 & $14.7 \%$ \\
Render & Male & 26 & $76.5 \%$ \\
& Female & 8 & $23.5 \%$ \\
\hline & Table 1. Personal Data of Residents \\
\hline
\end{tabular}

Table 1 depicts the age, level of residence and gender of residents, in which we found that $64.7 \%$ of respondents were less than thirty years of age. The mean age of all respondents and the standard deviation between the ages of respondents was 27.5 years and 2.8 respectively. The majority of respondents $(67.6 \%)$ were in the R1 level. The number of male respondents was more than three times compared to that of female respondents. Table 2 illustrates the various measures of causes of brain injury and preventive measures of brain injury reported by program residents. Out of all measures, the leading cause of brain injury was a car accident in which he / she became unconscious (94.1\%), followed by children striking their heads hard enough (76.5\%). The least common cause of brain injury reported by the program residents to be aware of any instance in early childhood was, as a baby, he / she was difficult to wake. i.e. (29.4\%). Cent per cent of respondents reported that not driving under the influence of alcohol or drugs was a preventive measure of brain injury. The most dominant preventive measures of brain injury were always wearing a seat belt in a motor vehicle $(97.1$ $\%)$, always wearing a helmet when on a bicycle, motorcycle, scooter, snowmobile and other open, unrestrained vehicles (97.1\%), use of an appropriate child safety seat or a booster (94.1\%), Placing bars on windows to prevent children from falling (94.1\%) and providing adequate lighting, especially on stairs for people with poor vision or who have difficulty in walking (91.2\%).

\begin{tabular}{|c|c|c|c|c|c|c|c|}
\hline \multirow{2}{*}{ Domain } & \multirow{2}{*}{ Items } & \multicolumn{2}{|r|}{ Yes } & \multicolumn{2}{|c|}{ No } & \multicolumn{2}{|c|}{ Don't know } \\
\hline & & No & $\%$ & No & $\%$ & No & $\%$ \\
\hline \multirow{6}{*}{ Causes of brain injury } & Car accident in which he / she was unconscious & 32 & $94.1 \%$ & 0 & $0.0 \%$ & 2 & $5.9 \%$ \\
\hline & Child ever struck his / her head hard enough & 26 & $76.5 \%$ & 2 & $5.9 \%$ & 6 & $17.6 \%$ \\
\hline & Aware of any instance in early childhood where, as a baby, he / she was difficult to wake & 10 & $29.4 \%$ & 16 & $47.1 \%$ & 8 & $23.5 \%$ \\
\hline & $\begin{array}{c}\text { Concussion / blow to the head while playing sports or other activity that was treated by a health care } \\
\text { professional }\end{array}$ & 19 & $55.9 \%$ & 5 & $14.7 \%$ & 10 & $29.4 \%$ \\
\hline & Assaults / violence (child abuse, firearm injury, fighting) & 28 & $82.4 \%$ & 5 & $14.7 \%$ & 1 & $2.9 \%$ \\
\hline & Whiplash injury to the neck & 18 & $52.9 \%$ & 5 & $14.7 \%$ & 11 & $32.4 \%$ \\
\hline \multirow{13}{*}{$\begin{array}{l}\text { Preventive measures } \\
\text { of brain injury }\end{array}$} & Always wear a seat belt in a motor vehicle & 33 & $97.1 \%$ & 1 & $2.9 \%$ & 0 & $0.0 \%$ \\
\hline & Use an appropriate child safety seat or a booster & 32 & $94.1 \%$ & 2 & $5.9 \%$ & 0 & $0.0 \%$ \\
\hline & Never drive under the influence of alcohol or drugs & 34 & $100.0 \%$ & 0 & $0.0 \%$ & 0 & $0.0 \%$ \\
\hline & $\begin{array}{l}\text { Always wear a helmet when on a bicycle, motorcycle, scooter, snowmobile and other open } \\
\text { unrestrained vehicles }\end{array}$ & 33 & $97.1 \%$ & 1 & $2.9 \%$ & 0 & $0.0 \%$ \\
\hline & Wear a helmet when participating in contact sports & 25 & $73.5 \%$ & 5 & $14.7 \%$ & 4 & $11.8 \%$ \\
\hline & Wear a helmet when horseback riding & 30 & $88.2 \%$ & 2 & $5.9 \%$ & 2 & $5.9 \%$ \\
\hline & Wear a helmet while skiing, snowboarding, skating and skateboarding. & 29 & $85.3 \%$ & 3 & $8.8 \%$ & 2 & $5.9 \%$ \\
\hline & Fall Prevention Methods & 30 & $88.2 \%$ & 2 & $5.9 \%$ & 2 & $5.9 \%$ \\
\hline & Use the rails on stairways & 20 & $58.8 \%$ & 3 & $8.8 \%$ & 11 & $32.4 \%$ \\
\hline & $\begin{array}{c}\text { Provide adequate lighting, especially on stairs for people with poor vision or who have difficulty } \\
\text { walking }\end{array}$ & 31 & $91.2 \%$ & 1 & $2.9 \%$ & 2 & $5.9 \%$ \\
\hline & Place bars on windows to prevent children from falling & 32 & $94.1 \%$ & 1 & $2.9 \%$ & 1 & $2.9 \%$ \\
\hline & Sit on safe stools & 23 & $67.6 \%$ & 4 & $11.8 \%$ & 7 & $20.6 \%$ \\
\hline & Do not place obstacles in walking pathways & 23 & $67.6 \%$ & 6 & $17.6 \%$ & 5 & $14.7 \%$ \\
\hline
\end{tabular}

\begin{tabular}{|c|c|c|c|c|c|c|}
\hline \multirow[b]{2}{*}{ Effect of Brain Injury } & \multicolumn{2}{|c|}{ Yes } & \multicolumn{2}{|c|}{ No } & \multicolumn{2}{|c|}{ Don't know } \\
\hline & No & $\%$ & No & $\%$ & No & $\%$ \\
\hline Head injury can cause brain damage even if the person is not knocked unconscious. & 19 & $55.9 \%$ & 3 & $8.8 \%$ & 12 & $35.3 \%$ \\
\hline $\begin{array}{l}\text { It is obvious that someone has brain damage because they look different from people who don't have brain } \\
\text { damage }\end{array}$ & 17 & $50.0 \%$ & 10 & $29.4 \%$ & 7 & $20.6 \%$ \\
\hline It is possible that a person's personality will change after a brain injury. & 29 & $85.3 \%$ & 1 & $2.9 \%$ & 4 & $11.8 \%$ \\
\hline Problems with irritability and difficulties controlling anger are common in people who have had a braininjury. & 16 & $47.1 \%$ & 3 & $8.8 \%$ & 15 & $44.1 \%$ \\
\hline Brain injuries may cause one to feel depressed, sad, and hopeless. & 24 & $70.6 \%$ & 4 & $11.8 \%$ & 6 & $17.6 \%$ \\
\hline People in a coma are usually not aware of what is happening around them. & 28 & $82.4 \%$ & 1 & $2.9 \%$ & 5 & $14.7 \%$ \\
\hline Even after several weeks in a coma, when people wake up, most recognize and speak to others right away. & 12 & $35.3 \%$ & 9 & $26.5 \%$ & 13 & $38.2 \%$ \\
\hline Sometimes a second blow to the head can help a person remember things that were forgotten. & 9 & $26.5 \%$ & 5 & $14.7 \%$ & 20 & $58.8 \%$ \\
\hline $\begin{array}{l}\text { A person with brain injury may have trouble remembering events that happened before the injury, but usually } \\
\text { does not have trouble learning new things. }\end{array}$ & 22 & $64.7 \%$ & 5 & $14.7 \%$ & 7 & $20.6 \%$ \\
\hline $\begin{array}{l}\text { People who have survived a brain injury can forget who they are and not recognize others but be normal in every } \\
\text { other way. }\end{array}$ & 17 & $50.0 \%$ & 4 & $11.8 \%$ & 13 & $38.2 \%$ \\
\hline Once a person can walk again, his or her brain is almost fully recovered. & 9 & $26.5 \%$ & 18 & $52.9 \%$ & 7 & $20.6 \%$ \\
\hline People who have had one brain injury are more likely to have a second one. & 10 & $29.4 \%$ & 10 & $29.4 \%$ & 14 & $41.2 \%$ \\
\hline Once a person recovering from brain injury feels "back to normal," the recovery process is complete. & 7 & $20.6 \%$ & 15 & $44.1 \%$ & 12 & $35.3 \%$ \\
\hline How quickly a person recovers depends mainly on how hard they work at recovering. & 15 & $44.1 \%$ & 11 & $32.4 \%$ & 8 & $23.5 \%$ \\
\hline Most people with brain damage are not fully aware of its Effect on their behaviour. & 18 & $52.9 \%$ & 7 & $20.6 \%$ & 9 & $26.5 \%$ \\
\hline Complete Recovery from a severe brain injury is not possible, no matter how badly a person wants to recover. & 10 & $29.4 \%$ & 13 & $38.2 \%$ & 11 & $32.4 \%$ \\
\hline It is common for people with brain injuries to be easily angered. & 14 & $41.2 \%$ & 3 & $8.8 \%$ & 17 & $50.0 \%$ \\
\hline $\begin{array}{l}\text { Asking someone who has had a brain injury about their progress is the most accurate, informative way to find out } \\
\text { how he / she has progressed. }\end{array}$ & 7 & $20.6 \%$ & 10 & $29.4 \%$ & 17 & $50.0 \%$ \\
\hline It is common for people to experience changes in behaviour after a brain injury. & 25 & $73.5 \%$ & 1 & $2.9 \%$ & 8 & $23.5 \%$ \\
\hline Recovery from a brain injury is usually complete in 5 months. & 3 & $8.8 \%$ & 8 & $23.5 \%$ & 23 & $67.6 \%$ \\
\hline
\end{tabular}


Table 3 describes the effects of brain injury as reported by program residents. There are multiple factors covered under the effects of brain injury. Nearly $55.9 \%$ reported that the head injury could cause brain damage even if the person is not knocked unconscious. Very few reported that the recovery from a brain injury is usually complete in about five months. Several factors affect brain injury, in which the most preferred effect reported by more than fifty percent of respondents was that a person's personality would change after a brain injury $(85.30 \%)$, followed by the other effects such as people in a coma are usually not aware of what is happening around them (82.40\%), common for people to experience changes in behaviour after a brain injury (73.50\%), brain injuries may cause one to feel depressed, sad, and hopeless (70.60\%), a person with brain injury may have trouble remembering events that happened before the injury, but usually does not have trouble learning new things (64.70\%), most people with brain damage are not fully aware of its effect on their behaviour ( $52.90 \%$ ), obvious that someone has brain damage because they look different from people who don't have brain damage $(50.00 \%)$ and people who have survived a brain injury could forget who they are and not recognize others but be normal in every other way. (50.00\%).

\section{DISCUSSION}

The degree of the TBI epidemic is harmonized only by the broad complexity of the cerebral pathophysiology involved. Injury severity, type and place, and age and gender all added to produce exclusive brain pathologies, meaning that no two TBIs are alike. Age and injury severity are very important in influencing the outcome. Motor vehicle or traffic related accidents are the leading causes of moderate to severe TBI in the US. ${ }^{5}$ The occurrence of sport related mild traumatic brain injury (TBI) is projected to be 130,000 per year among children of 5 - 18 years of age. ${ }^{11}$ The International Mission for Prognosis and Clinical Trial (IMPACT) record on TBI by including patient's information from eight randomized control trials and three observational surveys detected that growing age was directly connected to worse result in a continuous linear trend. 12

As defined in the studies that the TBI most frequently is seen in the young adults between 20 and 50 years, as another study reported incidence of TBI in the old age was less by others also. ${ }^{13,14}$ In addition, the mean age of all respondents in the present study was 27.5 years and the majority of respondents residing at the $\mathrm{R} 1$ level and considering severe growth in both these locations, where there is a rise in transportation vehicle load. Individuals travelling by different modes of vehicle are likely to cause accidents due to numerous reasons such as insufficient safety protocols or inappropriate road infrastructure. The area and mode of injury possibly play a role in the result. ${ }^{15-17}$

Retrospective cross-sectional study was conducted at Aseer Central Hospital ACH) Kingdom of Saudi Arabia, in which $87.3 \%$ males and $12.7 \%$ females were comprised and the results indicated that men were 2.4 times more often sustainable to TBI in their lifetime than women.18 Furthermore, the number of male respondents were more than three times compared to female respondents in the present study.

Another study in Saudi Arabia defined that males were more affected with head injury than females (78.4 \% VS 21.6 \%). ${ }^{19}$ These results were also similar to those of Jason Kisser (2017). ${ }^{20}$ Some research has revealed that the lack of selfawareness is related to poorer outcomes suggesting that selfawareness may be significant in rehabilitation. ${ }^{21-25} \mathrm{~A}$ frequently cited general description of self-awareness is the capacity to perceive the 'self' in relatively 'objective' terms, whereas continuing a sense of subjectivity. ${ }^{26}$ In relation to TBI research, 'lack of self-awareness' applies to incapability of identifying deficits that have resulted from a neurological injury. ${ }^{27,28}$ Research indicates that lack of self-awareness is a common difficulty in people who suffer from a moderate to severe TBI. ${ }^{29,30}$

Longitudinal studies further propose that self-awareness is more impaired directly after an injury, when most of the rehabilitation occurs, but improves over time. ${ }^{31}$ Poor selfawareness following TBI can result in decreased motivation, ${ }^{32}$ compromised safety due to impractical goals, 33,34 and impaired decision. The present study describes multiple factors under the effects of brain injury as reported by program residents. Some studies suggest that self-awareness deficits lead to more negative results. ${ }^{29,30}$ In a study, Sherer et al. ${ }^{30}$ reported that respondents with greater self-awareness, as measured by the Awareness Questionnaire (AQ), had higher employability rates. In the present study, majority of respondents had good awareness about preventive measures of brain injury. Owns worth and Clare, 25 in their review paper, determined that the majority of studies maintained or moderately maintained the knowledge that self-awareness deficits are related to poorer results. In dissimilarity, other work recommends that there is some sign of a relationship between self-awareness and results. ${ }^{21}$ About sixty per cent overall awareness level was reported in the present study by program residents regarding brain injury.

\section{CONCLUSIONS}

There is a need to strengthen the awareness about TBIs in the preventive program residents. Additional studies are required to assess the awareness regarding TBI in other regions among the preventive medicine postgraduates and other healthcare professionals. This will provide valuable feedback to the policymakers and the national prevention program managers.

Data sharing statement provided by the authors is available with the full text of this article at jemds.com.

Financial or other competing interests: None.

Disclosure forms provided by the authors are available with the full text of this article at jemds.com.

Authors are thankful to King Khalid University, Kingdom of Saudi Arabia, for providing all the technical support \& help. 


\section{REFERENCES}

[1] Accidental Deaths and Suicides in India. National Crime Records Bureau. Ministry of Home Affairs. New Delhi: Government of India 2014.

[2] Dewan MC, Rattani A, Gupta S, et al. Estimating the global Incidence of traumatic brain injury. J Neurosurg 2018;130(4):1080-97.

[3] Roozenbeek B, Maas AIR, Menon DK. Changing patterns in the epidemiology of traumatic brain injury. Nat Rev Neurol 2013;9(4):231-6.

[4] Maas AIR. Traumatic brain injury in India: a big problem in need of data. Neurol India 2017;65(2):257-8.

[5] Faul M, Xu L, Wald MM, et al. Traumatic brain injury in the United States: emergency department visits, hospitalizations and deaths 2002-2006. Atlanta, GA: Centers for Disease Control and Prevention 2010.

[6] Centers for Disease Control and Prevention (CDC). Congress on mild traumatic brain injury in the United States: steps to prevent a serious public health problem. Atlanta, GA: Centers for Disease Control and Prevention 2003.

[7] Gurusamy J, Gandhi S, Amudhan S, et al. Misconceptions about traumatic brain injury among nursing students in India: implications for nursing care and curriculum. BMC Nurs 2019;18:64.

[8] Ansari S, Akhdar F, Mandoorah M, et al. Causes and effects of road traffic accidents in Saudi Arabia. Public Health 2000;114(1):37-9.

[9] Isam S, Al Ghamdi A. Analysis of injuries resulting from road traffic accidents in Riyadh district. King Saud Mag Eng Sci 1996;8:235-50.

[10] Alhabdan S, Zamakhshary M, Alnaimi M, et al. Epidemiology of traumatic head injury in children and adolescents in amajor trauma center in Saudi Arabia: implications for injuryprevention. Ann Saudi Med 2013;33(1):52-6.

[11] Cohen JS, Gioia G, Atabaki S, et al. Sports-related concussions in pediatrics. Curr Opin Pediatr 2009;21(3):288-93.

[12] Mushkudiani NA, Engel DC, Steyerberg EW, et al. Prognostic value of demographic characteristics in traumatic brain injury: results from the IMPACT study. J Neurotrauma 2007;24(2):259-69.

[13] Prashant KG, Atul K, Amit ND, et al. CT scan findings and outcomes of head injury patients: a cross-sectional study. J Pak Med Sci 2011;1(3):78-82.

[14] Bharti P, Nagar AM, Umesh T. Pattern of trauma in Western Uttar Pradesh. Neurol India 1993;41:49-50.

[15] Chiu WT, Huang SJ, Tsai SH, et al. The impact of time, legislation and geography on the epidemiology of traumatic brain injury. J Clin Neurosci 2007;14(10):930-5.

[16] Feigin VL, Theadom A, Barker-Collo S, et al. Incidence of traumatic brain injury in New Zealand: a population-based study. Lancet Neurol 2013;12(1):53-64.

[17] Seid M, Azazh A, Enquselassie F, et al. Injury characteristics and outcome of road traffic accident among victims at adult emergency department of Tikur
Anbessa specialized hospital, Addis Ababa, Ethiopia: a prospective hospital-based study. BMC Emerg Med 2015;15:10.

[18] Alnaami I, Alshehri S, Alghamdi S, et al. Patterns, types and outcomes of head injury in aseer region, Kingdom of Saudi Arabia. Neuroscience J 2019;2019:2782146.

[19] Al-Habib A, A-Shail A, Alaqeel A, et al. Causes and patterns of adult traumatic head injuries in Saudi Arabia: implications for injury prevention. Ann Saudi Med 2013;33(4):351-5.

[20] Kisser J, Waldstein SR, Evans MK, et al. Lifetime prevalence of traumatic brain injury in a demographically diverse community sample. Brain Inj 2017;31(5):620-3.

[21] Cheng SKW, Man DWK. Management of impaired selfawareness in persons with traumatic brain injury. Brain Inj 2006;20(6):621-8.

[22] Fleming JM, Ownsworth T. A review of awareness interventions in brain injury rehabilitation. Neuropsychol Rehabil 2006;16(4):474-500.

[23] Goverover Y, Johnston MV, Toglia J, et al. Treatment to improve self-awareness in persons with acquired brain injury. Brain Inj 2007;21(9):913-23.

[24] Leung DPK, Liu KPY. Review of self-awareness and its clinical application in stroke rehabilitation. Int J Rehabil Res 2011;34(3):187-95.

[25] Ownsworth T, Clare L. The association between awareness deficits and rehabilitation outcome following acquired brain injury. Clin Psychol Rev 2006;26(6):78395.

[26] Pigatano GP, Schacter DL. Awareness of deficit after brain injury: clinical and theoretical issues. New York: Oxword University Press 1991.

[27] Barco PP, Crosson B, Bolesta MM, et al. Training awareness and compensation in postacute head injury rehabilitation. In: Kreutzer JS, Wehman PH, eds. Cognitive rehabilitation for persons with traumatic brain injury: a functional approach. England: Paul H. Brookes Publishing 1991:129-46.

[28] Fitzgerald MCC, Carton S, O'Keeffe F, et al. Impaired selfawareness following acquired brain injury: current theory, models and anatomical understanding. The Irish Journal of Psychology 2012;33(2-3):78-85.

[29] Sherer M, Bergloff P, Levin E, et al. Impaired awareness and employment outcome after traumatic brain injury. J Head Trauma Rehabil 1998;13(5):52-61.

[30] Sherer M, Hart T, Nick TG, et al. Early impaired selfawareness after traumatic brain injury. Arch Phys Med Rehabil 2003;84(2):168-76.

[31] Hart T, Seignourel PJ, Sherer M. A longitudinal study of awareness of deficit after moderate to severe traumatic brain injury. Neuropsychol Rehabil 2009;19(2):161-76.

[32] Simmond M, Fleming JM. Occupational therapy assessment of self-awareness following traumatic brain injury. British Journal of Occupational Therapy 2003;66(10):447-53.

[33] Fleming JM, Strong J, Ashton R. Self-awareness of deficits in adults with traumatic brain injury: how best to measure? Brain Inj 1996;10(1):1-15.

[34] McPherson KM, Kayes N, Weatherall M. A pilot study of self-regulation informed goal setting in people with traumatic brain injury. Clin Rehabil 2009;23(4):296-309. 